\title{
Augmented Reality in Military Applications
}

\author{
S.Gurusubramani., M.SureshAnand, J.JeganAmarnath, D.Sathishkumar, A.Sheela
}

\begin{abstract}
The Art of Modern Warfare has seen a significant shift with the onset of the 21st Century as Military Operations have become more diverse and intense in nature. The rise of insurgency and terrorism with the onset of the "War on Terror" led by the USA and its allies had led to a need where soldiers are more specifically trained in Military Operations in Urban Terrain (MOUT), Counter-Insurgency and Counter-Terrorism duties. This has prompted the enlistment of late headways done in the field of Computers and innovation like Augmented Reality (AR) into military applications to improve a soldier's battle-space knowledge as real-world objects can then be augmented onto the real-world environment to create better training facilities for the soldiers and help the soldier to adapt up to complex conditions and increment communitarian circumstance mindfulness among warriors occupied with high-hazard tasks. AR can limit inadvertent blow-back, increment risk markings like the likelihood of Improvised Explosive Devices (IEDs) and increment war zone observation. $A R$ in coming time would be viewed as a venturing stone to future military applications as an arranged correspondence framework would mean a minimal loss of life and maximum impact during Military Operations.
\end{abstract}

Index Terms: Military Operations, Augmented Reality, Battle-Space, Battlefield Augmented Reality System

\section{INTRODUCTION}

Augmented Reality can there be a lifeline as it will synchronize all the accessible information about the adversary he is likely confronting, with a particular algorithm pouring in just the most reasonable information to the fighter's wearable headsets enabling him to act quicker and particularly smarter. The strategy of "Act Fast, Act Smart" has some critical outcomes as a quick silly choice can get you slaughtered however with more particular data access can enable you to act better. AR can likewise be utilized in other Military Applications other than training soldiers in different orders like preparing Combat Medics in a field of Combat First Aid, preparing Combat Engineers like Sappers and Miners, Military Simulation by summarizing the three-dimensional nature of the earth to the advanced application to consider sensible activity information streaming in through the body wearable sets giving more easy to use information rather than a blend crush of assortment of pointless and helpful information frames, and more. The AR has been seeing various applications in the fields of entertainment and gaming like

Revised Manuscript Received on October 18, 2019.

S.Gurusubramani, Department of Computer Science Engineering, Sri Sairam Engineering College, Chennai.

M.SureshAnand, Department of Computer Science Engineering, Sri Sairam Engineering College, Chennai.

J.JeganAmarnath, D.Sathishkumar, A.Sheela, Department of Computer Science Engineering, Sri Sairam Engineering College, Chennai.
Pokémon GO or Snapchat [2]. The Augmented Reality is now being envisioned as one of the most profitable tech avenue in the future alongside Artificial Intelligence, Big Data and Internet of Things with the AR industry being valued at USD 767.67 Billion by 2025 along with Virtual Reality.

Augmented Reality in the field of Military Applications has been used by Fighter Pilots in a rough frame since decades in the type of Helmet Mounted Displays as the pilots used to wear these head-mounted sets enabling them to target missiles just by taking a gander at their objective [9][10]. It is additionally utilized for giving essential airship performance information like speed and elevation they are flying in, consistently on their headsets enabling them to design and react appropriately to that. The market for AR in Military Applications is just to blast in future as an April 2018 report expresses that the interest will ascend to some $\$ 1.79$ billion USD by 2025 with many countries understanding the boundless incorporation that AR furnishes to the trooper in the battle-space and how it will consider all the more innovatively determined future war zones [6]. Different countries have likewise been actualizing and testing AR to enhance their preparation and upkeep for more favourable arranging and execution. In this paper, we will examine different uses of AR in Military Applications, the difficulties related with AR and how to manage it to give a cheap, reliable and state of the art solution for tech-driven militaries [3].

\section{NEED FOR AUGMENTED REALITY IN MILITARY APPLICATIONS}

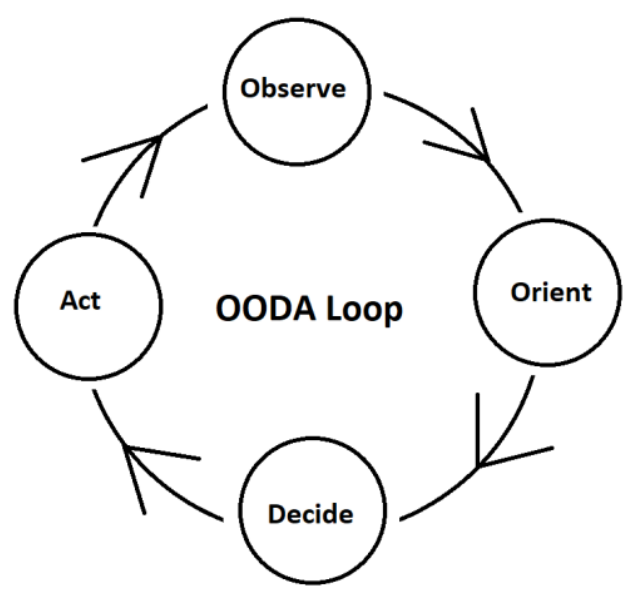

The developing consideration of 21st Century Technological Innovations in the field of Military Applications has been delivering wanted impacts particularly with the regularly changing usual methodology of the Art of Modern Warfare. This aims at reducing inadvertent

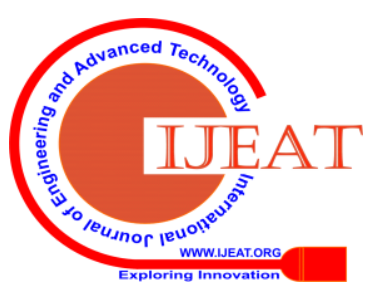




\section{Augmented Reality in Military Applications}

blow-back regarding lives and property with minimal collateral damage. A normal individual settle on normal of 35,000 choices every day which vary in their effect. The nature of basic leadership additionally matters a ton in Military Field as they can be a lifeline or have even unfavorable results. To process the boundless measure of information into our everyday choices, US Air Force Colonel John Boyd instituted the term OODA Loop-Observe, Orient, Decides and Act. This arranges our choices influencing capacities as an administrator to can see to unfurling occasions and after that figure his choice as indicated by it. In a real world scenario, this can be like when your platoon is ambushed by enemy fire, and you have to make

a quick decision on whether to call and wait for reinforcements or to retreat back to the base.

In a certifiable situation, this can resemble when your company is trapped by adversary fire, and you need to settle on a snappy choice on whether to call and sit tight for reinforcements or to withdraw back to the base. This choice depends on numerous information accessible to the Platoon Commander: the level of preparing of foe he is likely confronting, their weapons profile, and the risk level thus following Augmented Reality can there be a lifeline as it will synchronize all the accessible information about the adversary he is likely confronting, with a particular algorithm pouring in just the most reasonable information to the fighter's wearable headsets enabling him to act quicker and particularly smarter. The strategy of "Act Fast, Act Smart" have some critical outcomes as a quick silly choice can get you slaughtered however with more particular data accessible can enable you to act better. Augmented

Reality would allow for would consider a consistent reconciliation between the advanced and the physical world bringing another period of the man-machine interface where the dynamic and complex circumstances can be managed strongly with Augmented Reality Systems by expanding the Battlefield Perception and help jumble up the oft-said "mist of war" by 21 st Century forefront advances.

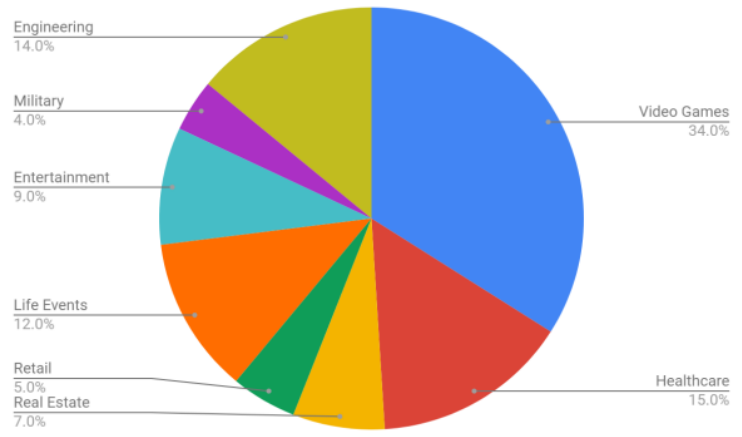

Fig: Augmented Reality in various applications (Source: CREDENCYS )

\section{Limitations OF Augmented ReAlity}

Augmented Reality can be achieved through multiple user collaboration and emphasizing on learning and adapting to new environments through the means of Artificial Intelligence to allow for better combat performance and combat enhancement of a warfighter. Computer Generated Graphics can be used for enhancing the familiarity with the environment bringing in prior experiences where the warfighter has trained in or has prior experience in. However Augmented Reality has shown in certain limitations which need to be addressed in critical time to make it a success in future applications. These are some of the limitations we have glanced upon which we want to emphasize:

\section{A. Input Medium}

The absence of Input Medium has been a glaring insufficiency in AR Sets. The utilization of consoles and mouse is lacking in an undeniable battle condition. Client Interactive means can be utilized like the touch screen and smartpen or more current innovations like Voice-Identification Means can be utilized however their common sense is yet to be tried on the open front line. Augmented Reality additionally chips away at-rule that a user ought not to be over-burden with pointless data and except if legitimate calculations are developed to sift through unsubstantial data, Augmented Reality would remain an open fantasy as AR must not meddle with the essential activities performed by the warfighter on the front line. Our proposed thought for an AR Input implies is either by voice directions, the most common route for correspondence crosswise over troopers with one another conveyed in battle, or for an all the more preparing serious utilization of Morse Codes through body developments like Eye Blinks to pass on certain coded directions to unite in all information. The info means ought to be worked in with most extreme respect to a Soldier's capacity to in any case battle while passing on the data as Input Means like Touch Screen can hinder free hand developments and influence battle ability.

\section{B. Information Overload}

Information Overload can cause a commotion on the Battlefield as in a high-stretch condition, unnecessary information jumbling on the Helmet Screen can be excessively agonizing, making it impossible to break down the outline of what is needful for us and what isn't. AR is intended to enhance the user's field of view and his battlespace learn- ing however that can likewise prevent his capacities if filtering algorithms are not taken appropriate consideration off. To address this result, the interface should be composed legitimately as giving just the most feasible information to the client according to his central goal and occupation profile. Until the point that the part of poor data summoning can be resolved, AR can't meet its maximum capacity on the combat zone. AR which goes about as an extension among Virtual and Real can't bear to lose itself in Information Processing and Management with the current 21st Century Technologies accessible.

\section{Depth Perception}

One of the biggest drawbacks of the AR utilization in Military is the Depth Perception it provides. Incorrect Depth Perception can hinder a soldier's capability as they need an unrestricted view to completely realize the threat level. Outdoors, the soldier might overestimate the depth while in indoors the user might underestimate the depth with prior knowledge of the world used to rectify the images shown on the AR headset. Our proposed idea includes the use of two cameras with a dense depth map being constructed by the use of pixels disparity and the distance between two cameras.

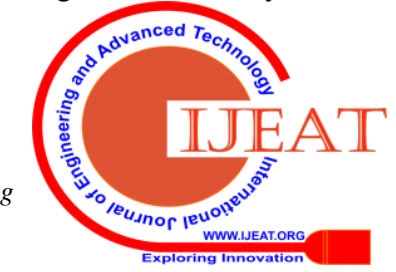


This can remove the calibration issues since the correct position of the image can then be calculated without any error in its depth and position in the $\mathrm{X}-\mathrm{Y}-\mathrm{Z}$ plane.

\section{Tracking Accuracy}

One of the baselines for the achievement of AR in Military Applications is its Tracking Ability, from that point forward just it is ready to adjust into the Real World Environment through Virtual Means. Construction of Cost-Affordable and rugged means for Tracking Measures must be managed to empower the Augmented Reality to be genuine progress. The greater part of Tracking Systems use Camera for Tracking Purposes anyway its precision in Combat Situations is debatable as, without intense Tracking Measures, AR would hold on to be a Toothless Tiger and more as an obstruction than an advantage.

\section{E. Hardware Costs}

Talking about Hardware, we tend to forget about the combat load out of an average soldier and the costs associated with it. On a normal, US Army spends as much as $\$ 17,500$ on a normal officer, referred to by Pentagon Officials in 2007 [5]. So the fundamental requirement for an AR System to be produced is that it must be genuinely modest to have the capacity to endure rivalry. New patterns in Military Technology are regularly met with hardened obstruction because of the over the top expenses related to it. We should likewise look onto different perspectives on how much load the AR Hardware puts onto the warrior. A normal warrior can take up to $25 \mathrm{~kg}$ of Battle Load in any situation alongside his Standard Issued Weapon which gauges somewhere in the range of $4 \mathrm{~kg}$. The AR System to be created ought to be structured as in and such not to put any additional Combat Load on the Soldiers generally this would vigorously influence the Combat Efficiency of the Soldier on the Battlefield and furthermore influence the Combat Manoeuvres where speed and accuracy is the only thing that is important.

Designing an AR System is an inherently complex task and requires extensive knowledge of sensors, information flow and the current needs of the 21st Century military and their warfare philosophy and spectrum. Virtual Fixtures were first developed at the United States Air Force Research Laboratory in 1992 and even more than 3 decades in the aftermath, AR is still considered new technology and has not seen any quotable degree of acceptance in militaries worldwide.

\section{APPLICATION}

Augmented Reality would find its best application in Military Training in-house with Training and Expertise Facilities and Schools. AR can likewise be utilized in other Military Applications other than training soldiers in different orders like preparing Combat Medics in a field of Combat First Aid, preparing Combat Engineers like Sappers and Miners, Military Simulation by summarizing the three-dimensional nature of the earth to the advanced application to consider sensible activity information streaming in through the body wearable sets giving more easy to use information rather than a blend crush of assortment of pointless and helpful information frames, and more.

In present, many of the Combat Troopers around the world are trained in Counter-Insurgency and Counter-Terrorism Operations around the world. Most of these operations take place in Urban and Semi-Urban Regions. Augmented Reality can be utilized to beef up Trainees in MOUT and Close Quarter Battles with simulated scenarios where the trainees can be pitted in various Combat Scenarios where their Combat Efficiency can be taken a test off. Various Training Facilities around the world have Kill-Houses and Simulated Villages, to allow the operators to take place in simulated Combat Operations. Augmented Reality can simulate a more Realistic Combat Operation by involving civilians and non-combatants and also involve opposing forces and simulated munitions to allow the operator believe that he is operating in a Real-World Environment and not in an unrealistic setup.

Military-Based Application of Augmented Reality Architectural Set-Up:

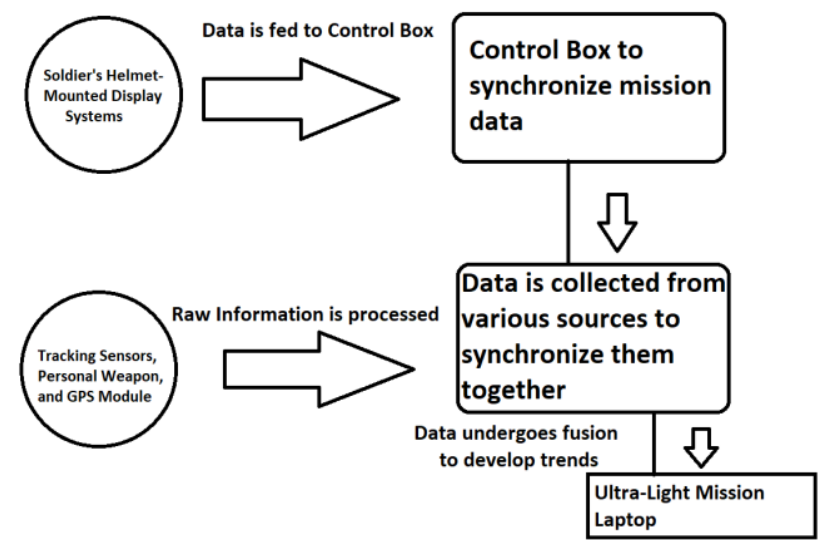

Fig: An Augmented Reality Architecture Set-Up

Such a training setup can also help to validate a Soldier's approach to a particular situation, his reaction time and then study his combat efficiency. Training using an AR System can also help the soldier to share the best practices with his fellow troopers and build their skills upon a common synergy conducive of the Training Purposes. Reality is like a beautiful canvas where we as a painter can do justice to it by painting beautiful colours for our own purposes. Take for example the Parachuting Exercise: A Paratrooper Trainee can often experience disorientation, nervousness and an overwhelming adrenaline rush giving him an unusual sensation which might take a toll on him, even after weeks of practices. Augmented Reality can do the job for him by putting him in a simulated yet credible enough environment where he can experience the jumping exercise and fit himself according to that. Augmented Reality provides the trainers and Instructors with an unmatched capability to deliver combat-specific content to trainees in order to train them in Situational Awareness and Combat Innovation.

Further applications of Augmented Reality would be found in hands-on Medical Services where Augmented Reality coupled with Artificial Intelligence and Machine Learning algorithms can provide

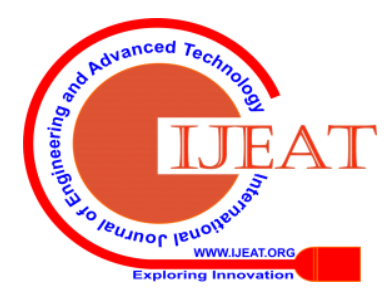




\section{Augmented Reality in Military Applications}

critical medical services to the casualties in the time of need. Battle Casualties can be tended to, even by medics who are not skilled enough to mend their injury, by connecting to an Augmented Reality headset where they would be imparted general instructions by better trained and experienced doctors and surgeons. These measures can extend the golden hour for the casualty, aided by technology. The past medical history of a soldier can also be analyzed by means of traditional Machine Learning Algorithm where his medical deviations like allergies can be analyzed and tended to during his treatment.

Augmented Reality can also be of great help for Weapons Maintenance. A well- trained and equipped military also tends to increased Weapons Maintenance like Battle Tanks, Artillery Guns, Fighter Jets and more and for this hands-on extensive training should be conducted to train the Military Engineers.

During many cases, if a weapon breaks down during use then the crew operating the weapon needs to wait for some time to get the Military Engineers to the spot where his weapons have broken down. Let's say, a Battle Tank has broken down in the Battlefield and the crew needs to analyze the problem with the tank and how they can fix it. With the aid of Augmented Reality they can quickly analyze the various parts in the Tank and which particular section has been fractured which would allow the engineers, save some critical time to get the tank moving, safe and sound.

The Augmented Reality can proof to be advantageous to various applications across the military, in training, maintenance, servicing and Combat Aid. Military Adoption of Augmented Reality can push the industry to new heights with militaries across the world wishing to integrate with new solutions to their woes and adding another dimension to their capabilities.

\section{CONCLUSION}

In this paper, we have reflected on how Augmented Reality can help the Military to combat Native Problems in the military in regards to Training and how technology can be beneficial to the Military Service, by means of Augmented Reality. The paper explores the various problems with Augmented Reality at the nascent stage of its adoption and explores some novel technical solutions to this along with how Augmented Reality can be advantageous at various military applications. This paper proposes various means on how Augmented Reality can be the technology that can refine the Military Technology in upcoming decades coupled with contemporary technological advances [7].

\section{REFERENCES}

1.

"The Lengthy History of Augmented Reality". Huffington Post. May $15,2016$.

How Augmented Reality Works. (2001, February 19). Retrieved from https://com puter.howstuffworks.com/augmented-reality3.htm

3. Milzarski, E. (2018, November 01). How AR technology could change the way future troops train. Retrieved from https://www.wearethemighty.com/gear-tech/military-

training-augmented-reality

4. Mbwpadmin. (2017, November 15). Cost Of Military Spending | MilitaryBases.com Blog. Retrieved from https://militarybases.com/military-articles/cost-of-military-spendin g/

5. Global Military Augmented Reality Market Estimated At $\$ 1.79$ Billion By 2025. (n.d.). Retrieved from https://www.techristic.com/global-military-augmented-reality-mar ket-estimated-at-1-79-billion-by-2025/

6. Morozov, M. (2018, September 28). Augmented reality in Military: AR Can Enhance Warfare and Training. Retrieved from https://jasoren.com/augmented-reality-mi litary/

7. Lynch, G. (2017, September 16). AR warfare: How the military is using augmented reality. Retrieved from https://www.techradar.com/news/death-becomes-ar-how-the-mili tary-is-using-augmented-reality..

\section{AUTHORS PROFILE}

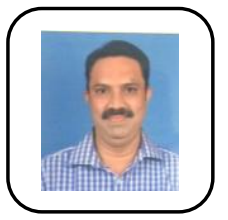

S.Gurusubramani, is working as an Associate professor/CSE in Sri Sairam engineering college, Chennai. He is having 20 years of experience in teaching. His areas of interest are e-learning, Computer networks, Cloud computing and Distributed systems. He also member in IAENG.

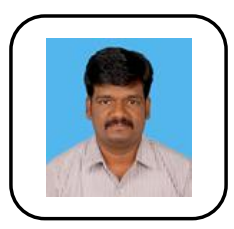

M.SureshAnand, is working as an Associate professor/CSE in Sri Sairam engineering college, Chennai. He had published more than 50 papers in reputed journals and conferences. He is having 15 years of experience in teaching. His areas of interest are Image Processing, Computer Vision, Machine Learning, Human Computer Interaction and Deep Learning. He also member in IAENG \& IACSIT.

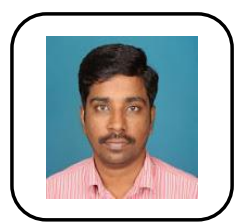

J.JeganAmarnath, is working as an Associate professor/CSE in Sri Sairam engineering college, Chennai. He had published papers in reputed journals and conferences. He is having 20 years of experience in teaching. He is a member in IAENG \& IACSIT. His areas of interest are Data mining, Soft computing, Artificial intelligence, Machine Learning, Human Computer Interaction and Deep Learning.

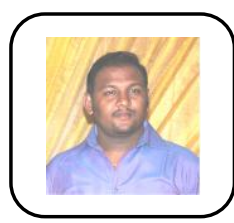

D.Satish Kumar, completed Bachelor degree (B.Tech) in Information Technology from anna University and Masters in Information Technology from Sathyabama University. Working as a Assistant Professor in Sri Sairam Engineering College, Chennai. Area of Research is networking and wireless communction. Life member of CSI, ISTE and IAENG.

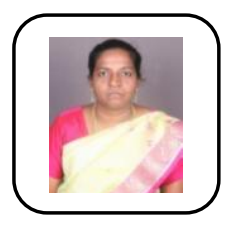

Sheela Working as Associate professor in Sri Sai Ram Engineering College for the past 17 years and completed MCA, M.Tech, M.Phil, handled many subjects few are Data Base Management System, Relational Data Base Management System, Computer Graphics, Computer Networks, Computer Architecture, Python Programming .The area of interest is Data Base Management System, Computer Networks. Organized and participated in various national levels Technical Symposium, FDPs, Staff Development programme, National Level seminars and workshops. Presented many papers in both national, international conferences and reputed International Journals. Having Life Membership in ISTE professional bodies and published paper in SCOPUS Journal. 